\title{
Low free testosterone levels in rheumatoid arthritis
}

\author{
T D SPECTOR, ${ }^{12}$ L A PERRY,${ }^{1}$ G TUBB, ${ }^{1}$ A J SILMAN ${ }^{2}$ AND \\ E C HUSKISSON ${ }^{1}$
}

From the ${ }^{1}$ Departments of Rheumatology and Reproductive Endocrinology, St Bartholomew's Hospital, West Smithfield, London; and the ${ }^{2}$ Department of Epidemiology, Bone and Joint Unit, The London Hospital, Whitechapel, London

SUMMARY The androgen status of 25 male patients with rheumatoid arthritis (RA) was assessed and compared with that of age matched controls with osteoarthritis (OA). Significantly reduced levels of serum free testosterone were found in the RA group. Within that group free testosterone was unrelated to all indices of disease activity measured, though it was strongly related to latex positivity. These results support the hypothesis that male sex hormones may have a protective role in RA, though prospective studies would be necessary to determine whether the relation was one of cause or effect.

Key words: androgens, sex hormones, gonadotrophins.

Recent attention has focused on the role of the sex hormones in the autoimmune diseases, ${ }^{1}$ both in the immunomodulation of the disease process and in their aetiology. ${ }^{2}$ One possible explanation for the lower incidence of rheumatoid arthritis (RA) in men than in women at all ages ${ }^{3}$ is that male sex hormones offer protection against the development of the disease. Studies have shown that with increasing age the sex difference for RA narrows, and the active androgens, free and serum testosterone, progressively decline. ${ }^{4}$ In this report androgen levels in men with rheumatoid arthritis are compared with those in age matched controls with generalised osteoarthritis (OA).

\section{Patients and methods}

Twenty five consecutive male patients attending a rheumatology clinic with definite or classical RA according to American Rheumatism Association criteria, aged 22 to 65 years (median age 57), were asked to participate in the study. Twenty seven male patients with generalised $\mathrm{OA}$, aged between 30 and 65 years (median age 55), attending the same clinic acted as controls. None of the patients had received steroids in any form in the past six months, and none had any evidence of liver disease, thyroid disease, or hypogonadism.

Accepted for publication 17 July 1987.

Correspondence to Dr T D Spector. Bone and Joint Unit, 25-29 Ashfield Street, London E1 2AD.
Information about drug treatments, weight, erythrocyte sedimentation rate (ESR), latex titres, clinical markers of disease activity (as represented by morning stiffness, articular index, and pain visual analogue scores), and length of disease duration were recorded for the patients with RA at the time of sampling. Blood was taken between $9 \cdot 30$ am and $11.30 \mathrm{am}$ in all patients and analysed for concentrations of testosterone, sex hormone binding globulin (SHBG), androstenedione, dehydroepiandrosterone sulphate (DHEAS), progesterone, luteinising hormone (LH), follicle stimulating hormone (FSH), and cortisol.

Hormonal analysis was by radioimmunoassay, ${ }^{5}$ and the 'derived free testosterone' was calculated using the formula of Anderson et $a l^{6}$ and given in pmolll. Hormone levels in the two groups were compared by Student's $t$ test. The RA group was then further subdivided into rheumatoid factor positive and negative cases, positive as defined by a latex titre above or equal to $1 / 40$ at the time of sampling. Comparisons between these subgroups were made using the Mann-Whitney $U$ test owing to the small numbers and distributions of the groups. Multiple regression was used to adjust for age and body weight as both can affect androgen levels.

\section{Results}

The results from the hormonal assays for the patients with RA and OA are shown in Table 1. The 
Table 1 Hormone levels in men with $R A$ and $O A$

\begin{tabular}{|c|c|c|c|}
\hline Hormone & $R A \quad(n=25)$ & $O A(n=27)$ & $p$ Valuet \\
\hline \multicolumn{4}{|l|}{ Testosterone } \\
\hline SHBG (nmol/l) & $26 \cdot 6(5 \cdot 2)$ & $24 \cdot 5(4 \cdot 2)$ & $0 \cdot 24$ \\
\hline \multicolumn{4}{|c|}{ Free testosterone } \\
\hline (pmol/l) & $323(100)$ & $457(268)$ & 0.024 \\
\hline LH (IU/I) & $6.96(3.8)$ & $7 \cdot 97(8 \cdot 8)$ & $0 \cdot 57$ \\
\hline FSH (IU/I) & $6.46(5 \cdot 5)$ & $5 \cdot 18(5 \cdot 05)$ & 0.48 \\
\hline \multicolumn{3}{|l|}{ Progesterone } & $0 \cdot 95$ \\
\hline $\begin{array}{l}\text { Androstenedione } \\
\text { (nmol/l) }\end{array}$ & $8.29(2.65)$ & $7 \cdot 7(3 \cdot 6)$ & $0 \cdot 51$ \\
\hline Cortisol (nmol/1) & $389(118)$ & $337(94.6)$ & $0 \cdot 084$ \\
\hline DHEAS $(\mu \mathrm{mol} / \mathrm{l})$ & $4 \cdot 31(2 \cdot 32)$ & $4 \cdot 15(3 \cdot 4)$ & 0.85 \\
\hline
\end{tabular}

*Values are mean (SD).

†Two tailed $t$ test.

men with RA had a non-significantly lower serum testosterone (means $15.3 \mathrm{nmol} / \mathrm{l} v 17.6 \mathrm{nmol} / \mathrm{l}$ ) and a significantly reduced derived free testosterone (means $323 \mathrm{pmol} / \mathrm{l} v 457 \mathrm{pmol} / \mathrm{l}, \mathrm{p}=0.02$ ). This difference persisted after adjusting for age and weight. No significant differences were noted for the other hormones measured, and though plasma cortisol was slightly higher in the men with RA, no correlation was found between cortisol levels and free or serum testosterone $(r=0.05, r=0.03)$.

Within the RA group, we were concerned that the low levels of free testosterone were dependent on the severity of the inflammatory disease at the time of sampling. The various measures of disease severity were therefore analysed to see whether they affected the levels of free testosterone. The rheumatoid factor status was the only disease variable measured found to affect hormone levels. The seropositive group had a significantly lower free testosterone level (medians seropositive $259 \mathrm{pmol} / \mathrm{l}$ and seronegative $399 \mathrm{pmol} / \mathrm{l}, \mathrm{p}=0.003$ ) and higher SHBG levels (medians 27.2 and $22.0 \mathrm{nmol} / \mathrm{l}$, $\mathrm{p}=0.004$ ) (Table 2). A significant negative correlation was found between the latex titre and free testosterone $(r=-0 \cdot 55, p<0 \cdot 01)$. Table 3 shows the

Table 2 Hormone levels and seropositivity status in $R A$

\begin{tabular}{llll}
\hline & $\begin{array}{l}\text { Latex+ }+ \\
\text { (median } n=16)\end{array}$ & $\begin{array}{l}\text { Latex- } \\
\text { (median } n=7)\end{array}$ & $p$ Value* $^{*}$ \\
\hline $\begin{array}{c}\text { Testosterone } \\
\text { (nmol/1) }\end{array}$ & $14 \cdot 3$ & $16 \cdot 5$ & $0 \cdot 67$ \\
$\begin{array}{l}\text { SHBG (nmol/1) } \\
\text { Free testosterone } \\
\text { (pmol/l) }\end{array}$ & $27 \cdot 2$ & $22 \cdot 0$ & $0 \cdot 0046^{* *}$ \\
\hline
\end{tabular}

*Two tailed, Mann-Whitney $U$ test; ${ }^{* *}$ significant $p$ value. tLatex + indicates titre $>1 / 40$.
Table 3 Free testosterone and disease activity

\begin{tabular}{|c|c|}
\hline Indicator of disease activity & $\begin{array}{l}\text { Correlation with free testosterowe } \\
(r \text { value })\end{array}$ \\
\hline ESR & $-0 \cdot 15$ \\
\hline Morning stiffness (minutes) & $+0 \cdot 04$ \\
\hline Pain (visual analogue scale) & +0.07 \\
\hline Disease duration (years) & $+0 \cdot 09$ \\
\hline Articular index (Ritchie) & $+0.63^{*}$ \\
\hline Latex titre & $-0 \cdot 55^{*}$ \\
\hline
\end{tabular}

correlations between the indices of disease activity measured and free testosterone. Only weak ans non-significant correlations were found between the level of free testosterone and ESR, length of morning stiffness, pain visual analogue score, and disease duration. The Ritchie articular index however, showed a significant positive correlation with free testosterone, an observation opposite in direction to that expected if disease activity e plained the lower level of free testosterone in megp with RA. A number of drugs were used by the patients with RA, including gold, penicillamine azathioprine, chlorambucil, and non-steroidal ant inflammatory drugs alone or in combination wi the above. No particular drug regimen was found be associated with low testosterone levels, though the numbers were small.

\section{Discussion}

The finding in this study of a lower mean fre⿳亠丷厂犬 testosterone level in male patients with RA than OA controls is consistent with the findings of others. One report of seven men with RA showed \& reduction in plasma androgens, ${ }^{7}$ and recently in study of sexual function, male patients with RA has reduced testosterone levels compared with controts with ankylosing spondylitis. ${ }^{8}$ In women with $\mathrm{R}$ abnormalities in urinary androgen excretion ${ }^{9}$ and reductions in plasma DHEAS have also been reported, ${ }^{10}$ though the numbers studied were smalis and the results have not been confirmed. ${ }^{11}$ Recentios two larger studies have produced conflicting results one showing no differences between cases and controls, ${ }^{12}$ and the other showing raised plasm androgens in postmenopausal women. ${ }^{13}$ The app $f^{2}$ cability of these data for women in interpreting the results of the present study is questionable, given the 10 times lower levels of testosterone in that group.

There are, however, a number of possible artefao tual explanations that may explain our results. Firstly, could the circulating immunoglobulis 
present in the serum of the seropositive patients have interfered with the hormonal assays? This is unlikely as the radioimmunoassays were performed using organic solvent extraction methods which effectively denature all endogenous serum binding proteins before assay. Further there was no effect of high latex titres on hormone levels in women with RA using the same assays. ${ }^{12}$

Secondly, could these observations have arisen purely by chance, particularly as some of the data seem inconsistent. Thus sex hormone binding globulin was not significantly raised in the patients with RA, as might have been expected given the lower free testosterone. The observed difference was, however, in the expected direction and was significantly higher when the analysis was restricted to seropositive patients. Free unbound testosterone is believed to be the principal active androgen in man, its levels being dependent on the reciprocal relationship between serum testosterone and SHBG, and is thus a more reliable indicator of androgen status than total serum testosterone alone.

Further, no rise in $\mathrm{LH}$ was seen in the patients with RA, as would normally be expected to compensate for the lower testosterone levels. This discrepancy is difficult to explain and is at variance with a previous report of high gonadotrophin levels in RA. ${ }^{8}$ A rise in $\mathrm{LH}$ could have been masked by the large individual variations in solitary gonadotrophin measurements. Alternatively, the data support a possible defect in the regulation of the pituitaryadrenocortical axis in RA. This defect may either be due to a primary dysfunction or to a failure of normal compensatory mechanisms. This is of interest considering the increasingly important role given to the immune system in modulating the pituitary-adrenocortical axis in humans, ${ }^{14}$ and of necropsy reports of a high frequency of hypophyseal abnormalities among patients with RA. ${ }^{15}$

Finally, the question remains as to whether the differences noted in this cross sectional study were merely an effect of the disease process, rather than suggesting an aetiological association. Thus free testosterone has been found to be reduced in severe disease states such as cancer and terminal renal failure, and it is possible, therefore, that the low free testosterone reflected a non-specific effect of disease severity, the patients with RA having more systemic disturbance than the controls with OA. The cases and controls, however, were essentially similar in that all were fully ambulant and were regular clinic attenders with chronic generalised arthritis, with no obvious differences in their general health. Further, no differences in adrenal function or adrenal androgens, such as DHEAS, were found, which would have been expected had any large differences in ill health existed. ${ }^{10}$ Although cortisol levels were slightly higher among the patients with RA, no correlation was found between cortisol and the level of androgens. Perhaps of more relevance was the lack of association between free testosterone levels and any of the indicators of disease severity tested. Indeed the positive correlation between the articular index and testosterone makes it unlikely that present disease activity accounted for the differences in testosterone. The possibility that disease activity several years previously could have influenced current androgen levels cannot be discounted.

Interestingly, seropositive patients classified on the basis of a single latex test had significantly lower levels of free testosterone than seronegative cases. This observation is strengthened as the variable nature of rheumatoid factor status in individuals, based on single estimates, would tend to mask differences, and the current results could thus underestimate the real differences in testosterone. Biologically this observation could indicate a possible relation between hormonal and immune mechanisms as has been shown by the immunoprotective effect of pituitary hormones and androgens in animal models. ${ }^{17} 18$

In conclusion these data are consistent with the hypothesis that low free testosterone levels are associated with RA in men. Prospective studies would be necessary to determine whether this relationship was one of cause or effect. These findings should encourage further work into hormonal modulation of the disease and genetic influences on hormonal levels in RA.

We thank Mrs Alison Greenwood for her help in performing the rheumatological assessments.

\section{References}

1 Lahita R G. Sex steroids and the rheumatic diseases. Arthritis Rheum 1985; 28: 121-6.

2 Inman RD. Immunologic sex differences and the female predominance in systemic lupus erythematosus. Arthritis Rheum 1978; 21: 849-51.

3 Linos A, Worthington J W, O'Fallon M W, Kurland L T. The epidemiology of rheumatoid arthritis in Rochester, Minnesota: a study of incidence, prevalence and mortality. Am J Epidemiol 1980; 1 : 87-98.

4 Davidson J M, Chen J J, Crapo L, Gray G D, Greenleaf W J, Catania $J$ A. Hormonal changes and sexual function in aging men. J Clin Endocrinol Metab 1983; 57: 71-7.

5 Wathen N C, Perry L A, Rubenstein E, Chard T. A relationship between sex hormone binding globulin and dehydroepiandrosterone sulphate in normally menstruating females. Gynaecol Endocrinol (in press).

6 Anderson D C, Thorner M O, Fisher R A, Woodham J P, Goble H L, Besser G M. Effects of hormonal treatment on plasma unbound androgen levels in hirsute women. Acta Endocrinol [Suppl] (Copenh) 1975; 80: 199-224.

7 Cutolo M, Balleari E, Accardo S, et al. Preliminary results of 
serum androgen level testing in men with rheumatoid arthritis. Arthritis Rheum 1984; 27: 958-9.

8 Gordon D. Beastall G H. Thomson J A. Sturrock R D. Androgenic status and sexual function in males with rheumatoid arthritis and ankylosing spondylitis. $Q J$ Med 1986; 231: 671-9.

9 Masi A T. Josipovic D B. Jefferson W E. Low adrenal androgenic-anabolic steroids in women with rheumatoid arthritis: gas liquid chromatographic studies of RA patients and matched normal control women indicating decreased 11-deoxy17-ketosteroid excretion. Semin Arthritis Rheum 1984: 14: 1-23.

10 Feher K G. Feher T. Plasma dehydroepiandrosterone, dehydroepiandrosterone sulphate and androsterone sulphate levels and their interaction with plasma proteins in rheumatoid arthritis. Exp Clin Endocrinol 1984; 84: 197-202.

11 Dougados M. Nahoul K. Benhamou L. Amor B. Androgen plasma levels in female rheumatoid arthritis patients. Arthritis Rheum 1983; 26: 935-6.

12 Spector T D. Perry L A. Tubb G. Huskisson E C. Androgen status of women with rhcumatoid arthritis. $\mathrm{Br} J$ Rheumat 1987: 26: $316-8$.

13 Cutolo M. Balleari E. Giusti M. Monachesi M. Accardo S. S hormone status in women suffering from rheumatoid arthriti J Rheumatol 1986; 13: 1019-23.

14 Blalock J E. Smith E M. Mever W J. The pituitars adrenocortical axis and the immune system. Clin Endocrin Metab 1985: 14: 1021-39.

15 Pearse A G E. The hypophysis in rheumatoid arthritis. Lanc है 1950: i: $954-5$.

16 Parker L N. Levin E R. Lifrak E T. Evidence for adrenocortici্ adaptation to severe illness. J Clin Endocrinol Metab 1985: 60: $947-52$.

17 Berczi I. Nagy E. Asa S L. Kovacs K. The influence of pituita hormones on adjuvant arthritis. Arthritis Rheum 1984; 2 $682-8$.

18 Allen J B. Blatter D. Calandra G. Wilder R L. Sex hormonad effects on the severity of streptococcal cell wall-induced polvarthritis in the rat. Arthritis Rheum 1983: 26: 560-3. O) 